\author{
발효탄수화물 첨가 비육돈사료가 초지환원용 슬러리의 악취물질 농도에 \\ 미치는 영향 \\ 조성백 ${ }^{1} \cdot$ 황옥화 $^{1} \cdot$ 박규현 $^{1} \cdot$ 최동윤 $^{1} \cdot$ 양승봉 $^{2} \cdot$ 김두환 $^{3} \cdot$ 박성권 $^{1}{ }^{*}$ \\ ${ }^{1}$ 농촌진흥청 국립축산과학원, ${ }^{2}$ 울산대학교, ${ }^{3}$ 경남과학기술대학교
}

\title{
The Effect of the Addition of Carbohydrate Sources on the Concentration of Odorous Compounds for Recycling of Pig Slurry to Grassland
}

\author{
Sung Back Cho ${ }^{1}$, Ok Hwa Hwang ${ }^{1}$, Kyu Hyeun Park ${ }^{1}$, Dong Yun Choi ${ }^{1}$, Seung Bong Yang ${ }^{2}$, Do Hwan Kim ${ }^{3}$ \\ and Sung Kwon Park ${ }^{1 *}$ \\ ${ }^{1}$ National Institute of Animal Science, RDA. Suwon 441-706, Korea, ${ }^{2}$ Ulsan University, Ulsan 680-749, Korea, \\ ${ }^{3}$ Gyeongnam National University of Science and Technology, Jinju 660-758, Korea
}

\begin{abstract}
This study investigates the effect of fermentable carbohydrate on the concentration of odorous compounds in pig slurry. Four types of pig diet were studied: control, peanut hull (crude fiber 29.87, NDF 44.02\%), golden fiber (crude fiber 48.77, NDF 65.88\%), and almond hull (crude fiber 44.30, NDF 64.44\%). Pigs (average BW $37.0 \mathrm{~kg}$ ) were fed diets that met the Korean Feeding Standard (2012) and their excreta samples were collected from the slurry pits. Levels of volatile organic compounds (phenols and indoles) and volatile fatty acids were analyzed by gas chromatography. Phenol level was the lowest $(p<0.05)$ in golden fiber (33.26 ppm) group and the highest in control $(97.29 \mathrm{ppm})$. The concentration of indoles in the peanut hull (1.27 $\mathrm{ppm})$, almond hull $(1.20 \mathrm{ppm})$, and golden fiber $(1.02 \mathrm{ppm})$ groups was lower $(\mathrm{p}<0.05)$ than that of control $(1.79 \mathrm{ppm})$. Levels of short chain fatty acid (SCFA) were lower $(\mathrm{p}<0.05)$ in golden fiber $(1,319 \mathrm{ppm})$ and almond hull $(1,433$ ppm $)$ groups than in control $(1,893 \mathrm{ppm})$. Concentration of branched chain fatty acid (BCFA) in the golden fiber group (74 ppm) was lower $(\mathrm{p}<0.05)$ than that of control $(98 \mathrm{ppm})$. Taken together, the concentration levels of phenols, indoles, and VFAs decreased on addition of peanut hull, golden fiber or almond hull to the diet, suggesting that fermentable carbohydrate may contribute to reducing odorous compounds in pig slurry.
\end{abstract}

(Key words : Pig slurry, Odor, fermentable carbohydrate, Volatile organic compound, Volatile fatty acid)

\section{I. 서 론}

2005년도에 축산시설에서 배설되는 악취를 규제하기 시 작한 이래(악취방지법, 2005), 양돈 시설에서 발생되는 악 취 민원이 축산유래 악취 민원의 $54 \%$ 를 차지하고 있다 (Ministry of Environment, Korea, 2006). 가축의 분뇨는 매 우 가치 있는 비료임에도 불구하고, 악취로 인해 비경제적 으로 정화되어 방류되는 경우가 많다. 경제적인 악취저감 기술개발로 환경오염을 최소화하여 분뇨를 초지나 조사료 포 등의 경지에 환원을 하여 생태계 순환의 흐름 속에 넣 어주는 노력이 필요하다.
사료를 통하여 섭취된 영양소와 내생 물질이 분과 뇨를 통해 배설되면 혐기 발효되어 휘발성 지방산(VFA : Volatile Fatty Acid), 페놀류, 인돌류, 암모니아 등의 악취 물질이 생성된다(Schaefer, 1977; Williams and Evans, 1981). 이들 물질 중에서 페놀류와 인돌류는 각각 타이로 신과 트립토판이 분해되어 생산되는 물질로서 악취 감지 최소농도가 낮고, 축사와 멀리 떨어진 곳까지 이동하면서 강한 악취를 발생한다(Zahn et al., 2001; Conn et al., 2007; Parker et al., 2012). 페놀 화합물 중 p-크레졸은 페놀에 비 해 분뇨에 높은 농도로 존재하고, 인돌 화합물인 스카톨과 인돌의 농도는 서로 부의 상관관계를 가진다 $(\mathrm{Li}$ et al.,

\footnotetext{
* Corresponding author: Sung Kwon Park. Animal Environment Division, National Institute of Animal Science, RDA. Suwon 441-706,
} Korea, Tel: +82-31-290-1657, E-mail: maiky@korea.kr 
2009). 단쇄지방산(SCFA : Short Chain Fatty Acid)은 탄수 화물 또는 L-글루타민, L-라이신 및 L-알라닌 등의 일부 아미노산이 분해되어 생성되지만, 이소부티르산 및 이소발 레르산과 같은 측쇄지방산(BCFA : Branched Chain Fatty Acid)은 단백질 분해과정에서 생성된다. 분뇨에서 $\mathrm{VFA}$ 의 분포를 살펴보면 총 $\mathrm{VFA}$ 의 $60 \%$ 정도는 아세트산이고, 다 음으로 프로피온산, 부티르산, 이소부티르산, 이소발레르산 순이다(McGill and Jackson, 1977; Cooper and Cornforth, 1978; Spoelstra, 1980). 돼지 분뇨에 있는 SCFA는 VFA 중 에서 비율이 높지만 불쾌도가 낮다(Mackie, 1994).

가축의 체내 또는 분뇨에서 미생물은 증식을 위해 단백 질을 이용하고, 에너지원으로 발효탄수화물을 이용한다 (Gibson and Roberfroid, 1995). 발효탄수화물의 양이 적거 나 발효탄수화물에 비하여 단백질이 많으면 미생물은 에너 지원으로 단백질을 사용하기 때문에, 악취물질이 많이 생 성될 수 있다(Reid and Hillman, 1999; Sutton et al., 1999; Le et al., 2008). 발효탄수화물(Fermentable Carbohydrates; 발효가능한 탄수화물)은 쉽게 분해되는 성분(이눌린, 전분 등)과 분해가 느린 성분(헤미셀룰로오스, 셀룰로오스 등)으 로 구성된다(Overland et al., 2011). 돼지의 대장 및 슬러리 발효환경을 개선하고자 두 가지 성분을 함께 이용하여 악 취물질을 조절하는 연구가 수행되고 있다(Le et al., 2008; Li et al., 2009; Miller and Varel, 2003). 따라서 악취물질 저감에 효과적인 발효탄수화물을 사료나 분뇨에 첨가하여 단백질과 발효탄수화물의 비율이 최적화되면 축사 시설의 악취가 감소 될 것으로 기대된다. 본 연구에서는 양돈 농 장에서 발생되는 악취를 줄이기 위하여 비육돈사료에 다양 한 종류의 발효탄수화물을 첨가한 다음 분뇨에서 발생되는 악취물질의 농도를 비교하기 위하여 수행되었다.

\section{ㅍ. 재료 및 방법}

\section{1. 시험 디자인 및 동물 및 사료}

시험구는 대조구, 땅콩껍질구, 골든화이버구 및 아몬드피 구로 하여 4 개 처리로 구성되었다. 처리구당 1 개 돈방에 평균체중 $37.0 \mathrm{~kg}$ 의 육성돈 암퇘지 20 두[(렌드레이스 $\times$ 요크 셔) $\times$ 듀록]를 난괴법 (RCB : Randomized Block Design)으로 5 두씩 배치하였다. 돈사 온도는 자동조절 열풍기 및 배기 팬을 이용하여 약 $25^{\circ} \mathrm{C}$ 를 유지하였다.

\section{2. 시험사료 제조 및 사료급여}

한국돼지사양표준(2012)의 영양소 요구량을 충족하도록 기초사료를 제조하였다(Table 1). 그리고 기초사료에 분쇄 된 공시 사료원료를 $0.5 \%$ 첨가하여 시험사료를 배합하였 다. 시험에 공시된 원료사료는 땅콩껍질(조섬유 29.87, $\mathrm{NDF} 44.02 \%$ ), 골든화이버(조섬유 48.77, $\mathrm{NDF} 65.88 \%$ ) 및 아몬드피 (조섬유 44.30, NDF 64.44\%) 이었다. 시험기간 35 일 동안 체중의 $3 \%$ 사료를 1 일 2회(09:00, 16:00) 나누어 급여 하였다.

Table 1. Formula of the basic diets

\begin{tabular}{lc}
\hline Ingredients & Formula (\%) \\
\hline \hline Corn, yellow & 56.65 \\
Soybean meal & 33.04 \\
Molasses & 5.00 \\
Sugar & 3.00 \\
Limestone & 0.79 \\
Dicalcium phosphate & 0.54 \\
Soybean oil & 0.29 \\
Salt & 0.25 \\
Vitamin Mixture & $1)$ \\
Vitamin Mixture & 0.15 \\
L-lysine $\cdot \mathrm{HCl}$ & 0.20 \\
Total & 0.09 \\
\hline
\end{tabular}

\begin{tabular}{lc}
\hline Composition calculated & 20.0 \\
Protein (\%) & 3,400 \\
DE (kcal/kg) & 3.50 \\
Crude fiber (\%) & 0.60 \\
Ca (\%) & 0.50 \\
P (\%) & 1.15 \\
Lysine (\%) & 0.30 \\
Methionine (\%) & 0.76 \\
Threonine (\%) & 0.25 \\
Tryptophan (\%) & \\
\hline 1) Provided the following per kilogram of diet : choline chloride 700 \\
mg, selenium 0.15 mg, manganese 0.03 g, zinc 0.1 g, iron 0.1 g, \\
iodine 0.5 mg, magnesium 0.1 g. \\
2) Provided the following amounts per kilogram of diet : vitamin A \\
5,500 IU; vitamin $\mathrm{D}_{3} 550$ IU; vitamin E 27 IU; menadione sodium \\
bisulfate 2.5 mg; pantothenic acid 27 mg; niacin 33 mg; riboflavin \\
5.5 mg; vitamin $\mathrm{B}_{12} 0.04$ mg; thiamin 5 mg; pyridoxine 3 mg; biotin \\
0.24 mg; folic acid 1.5 mg; choline chloride 700 mg.
\end{tabular}




\section{3. 분뇨 채취}

악취물질 분석용 분뇨는 사양시험 개시 후 2주째부터 5 주 동안 매주 채취하여 총 4회에 걸쳐 채취되었다. 돈방 별로 구획되어 있는 피트의 슬러리 배출구를 이용하여 슬 러리 전량을 1 차로 채취한 다음 균질화 과정을 거쳐 2차로 분석용 시료를 $500 \mathrm{ml}$ 채취하였다. 2차로 채취된 시료는 화학분석에 이용되기 전까지 냉동고에 보관되었다.

\section{4. 악취물질 분석}

$\mathrm{VFA}$ 를 분석하기 위한 시료는 $25 \%$ 인산용액을 이용하여 전처리 한 후 준비되었고, $\mathrm{VOC}$ (Volatile Organic Compound) 분석용 시료는 Jensen et al.(1995)의 방법에 따라 준비한 후 Gas Chromatography (6890N, Agilent, USA)를 이용하여 분석되었다. Inlet과 detector의 온도는 $250^{\circ} \mathrm{C}$ 로 하였고, Split ratio는 VFA 10:1과 VOC 5:1로 설정하였다. column은 직 경 $0.25 \mathrm{~mm}$, 길이 $30 \mathrm{~m}$ 의 HP-INNOWax와 DB-1을 각각 사 용하였다. 검출기는 두 물질 모두 FID (Flame Ionization Detector)를 이용하였다. 암모니아태 질소(Ammonium Nitrogen $\left.: \mathrm{NH}_{4}{ }^{+} \mathrm{-N}\right)$ 은 시료 내 암모니아를 황산용액에 흡수시키고 수산화나트륨 용액으로 적정하는 중화적정법으로 전처리하 고 켈달질소분해장치(1035 Analysis, Foss, Denmark)를 이 용하여 분석되었다. $\mathrm{pH}$ 는 $\mathrm{pH}$ meter (850C, Schott, Germany) 를 이용하여 측정되었다.

\section{5. 통계처리}

모든 실험은 각각 4반복으로 실험을 하였으며, 실험결과 에 대한 통계분석은 SAS (Statistical Analysis System, 1996) package GLM (General Linear Model)을 이용하여 분산분석 을 실시하였고, 평균간 차이는 Duncan (1955)의 다중검정법 에 의해 $95 \%$ 유의수준으로 분석되었다.

\section{III. 결과 및 고찰}

\section{1. 슬러리의 VFA 농도 변화}

발효탄수화물을 사료에 첨가하여 돼지에 급여한 다음 돈 사 피트에서 채취한 분뇨의 VFA 농도를 분석한 결과는 Table 2와 같다. SCFA 농도는 대조구, 땅콩껍질, 아몬드피 및 골든화이버 구에서 각각 $1,893,1,591,1,433$ 및 1,319 $\mathrm{ppm}$ 으로 대조구에서 가장 높았고 $(\mathrm{p}<0.05)$, 아몬드피와 골 든파이버 구에서 가장 낮았다 $(\mathrm{p}<0.05) . \mathrm{VFA}$ 의 구성을 살 펴보면 SCFA 중에서 아세트산의 비율이 가장 높으며, 다 음으로 프로피온산, 부티르산, BCFA 순으로 낮았는데, 이 것은 다른 연구자의 시험결과와 비슷하였다 $(\mathrm{Wu}$ et al., 1999). 아세트산, 프로피온산 및 부티르산과 같은 SCFA는 탄수화물과 단백질로부터 생성되지만, i-부티르산 및 i-발레 르산과 같은 $\mathrm{BCFA}$ 는 단백질이 분해되는 경우에만 생성된 다(Jensen and Jorgensen, 1994), 팽이버섯폐배지 (NDF 75.0\%,

Table 2. Effects of fermentable carbohydrate sources on the VFA concentration from slurry of pigs ${ }^{1)}$

\begin{tabular}{|c|c|c|c|c|c|}
\hline \multirow{2}{*}{ VFA (ppm) } & \multicolumn{4}{|c|}{ Fermentable carbohydrate source } & \multirow{2}{*}{ SEM } \\
\hline & Control & Peanut hull' ${ }^{2)}$ & Almond hull $^{2)}$ & Golden fiber $^{2)}$ & \\
\hline Acetic acid & $1,597^{\mathrm{a}}$ & $1,265^{\mathrm{b}}$ & $1,162^{b c}$ & $1,042^{c}$ & 38.96 \\
\hline Propionic acid & $186^{\mathrm{ab}}$ & $200^{\mathrm{a}}$ & $162^{\mathrm{b}}$ & $172^{\mathrm{ab}}$ & 5.47 \\
\hline Butyric acid & 110 & 126 & 110 & 105 & 5.17 \\
\hline i-Butyric acid & $29^{\mathrm{a}}$ & $29^{\mathrm{a}}$ & $25^{\mathrm{ab}}$ & $24^{\mathrm{b}}$ & 0.87 \\
\hline i-Valeric acid & $69^{\mathrm{a}}$ & $63^{\mathrm{ab}}$ & $53^{\mathrm{bc}}$ & $50^{\mathrm{c}}$ & 1.91 \\
\hline SCFA $^{3)}$ & $1,893^{\mathrm{a}}$ & $1,591^{\mathrm{b}}$ & $1,433^{\mathrm{c}}$ & $1,319^{\mathrm{c}}$ & 41.03 \\
\hline $\mathrm{BCFA}^{4)}$ & $98^{\mathrm{a}}$ & $92^{\mathrm{ab}}$ & $78^{\mathrm{bc}}$ & $74^{\mathrm{c}}$ & 2.76 \\
\hline
\end{tabular}

${ }^{1)}$ Composition of pig diet : Protein 16.5\%, DE 3,450 kcal $/ \mathrm{kg}$, Fiber 3.4\%, Ca $0.8 \%$, P 0.65\%, Lysine 0.87\%, Methionine $0.27 \%$, Threonine $0.63 \%$, Tryptophan $0.19 \%$.

${ }^{2)}$ Composition of fermentable carbohydrate source : Peanut hull, Crude fiber $29.87 \%$, NDF $44.02 \%$; Golden fiber, Crude fiber $48.77 \%$, NDF $65.88 \%$; Almond hull, Crude fiber $44.30 \%$, NDF $64.44 \%$. Fermentable carbohydrate sources were added $0.5 \%$ in basic diet.

${ }^{3)}$ SCFA(Short Chain Fatty Acid) = Acetic acid + Propionic acid + Butyric acid.

${ }^{4)}$ BCFA (Branched Chain Fatty Acid) = i-Butyric acid + i-Valeric acid.

${ }^{\mathrm{a}, \mathrm{b}, \mathrm{c}, \mathrm{d}}$ Figures with different superscripts within the same row are significantly different $(\mathrm{p}<0.05)$. 
$\mathrm{NFC} 6.9 \%$ ), 아몬드피 (NDF $30.0 \%$, NFC 54.3\%), 비트펄프 (NDF $41.7 \%, \mathrm{NFC} 38.3 \%$ )에는 발효탄수화물이 많이 포함 되어 있기 때문에 (Getachew et al., 2004; Kim et al., 2007), 탄수화물 발효가 활발히 일어날 수 있다.

$\mathrm{BCFA}$ 의 농도는 대조구, 땅콩껍질, 아몬드피 및 골든화 이버 구에서 각각 $98,92,78$ 및 $74 \mathrm{ppm}$ 으로 대조구에서 가장 높았고 $(\mathrm{p}<0.05)$, 골든화이버 구에서 가장 낮았다 $(\mathrm{p}<0.05)$. 따라서 공시된 발효탄수화물 중에서 땅콩껍질이 가장 많은 단백질발효가 있었고, 골든화이버에서 탄수화물 이 많이 발효되었다고 추정된다. 저항성 전분 $(300 \mathrm{~g} / \mathrm{kg})$ 이 첨가된 비육돈 사료를 급여하였을 때, 분과 공기 중의 인 돌 및 $\mathrm{BCFA}$ 의 농도가 감소되었다는 보고가 있다(Willing et al., 2005). BCFA는 단백질이 분해되어 생성되는 물질로 서 (Le et al., 2005), 대조구에서는 단백질 발효가 많이 일 어난 것으로 판단된다.

일반적으로 $\mathrm{VFA}$ 는 $\mathrm{SCFA}$ 가 $70 \%$ 를 차지하고 있으며 (Cooper and Cornforth, 1978), 한국 사람들의 경우 김치와 같은 발효식품을 섭취하기 때문에 SCFA를 불쾌하게 느끼 지 않는 경향이 있어 악취에 미치는 강도가 크지는 않은 것 같다.

2. 슬러리의 VOC 농도 변화
페놀류, 인돌류 및 $\mathrm{NH}_{4}{ }^{+}-\mathrm{N}$ 농도는 Table 3 과 같다. 페놀 류 농도는 대조구, 땅콩껍질, 아몬드피 및 골든화이버 구에 서 각각 97.3, 47.0, 54.3 및 $33.3 \mathrm{ppm}$ 으로 골든화이버 구 에서 가장 낮았으며, 대조구에서 가장 높았다 $(\mathrm{p}<0.05)$. $\mathrm{p}$-크레졸 농도가 페놀류 농도의 93 96\%를 차지하였다. Spoelstra (1977)의 연구에서도 돼지 슬러리의 페놀 농도가 $\mathrm{p}$-크레졸의 $10 \%$ 이하라고 하였다.

인돌류 농도는 대조구, 땅콩껍질, 아몬드피 및 골든화이 버 구에서 각각 $1.8,1.3,1.2$ 및 $1.0 \mathrm{ppm}$ 으로 발효탄수화물 처리구간에 차이가 없었으며 $(\mathrm{p}>0.05)$, 대조구에서 가장 높 았다 $(\mathrm{p}<0.05)$. 양돈 사료에 치커리 이눌린 (Rideout et al., 2004), 비트펄프 (Knarreborg et al., 2002), 이눌린과 감자전 분 (Overland et al., 2011), 팽이버섯폐배지 (Lee et al., 2012) 및 저항성 감자 전분 (Rideout et al., 2004; Willing et al., 2005)을 첨가하였을 때 돼지 분뇨에서 스카톨 농도 가 감소되었다. Goa et al.(1999)은 기초사료에 섬유소를 첨가함으로써 신선분에서 $\mathrm{p}$-크레졸과 스카톨의 발생량이 감소되었다고 하였다. 돼지에 발효탄수화물을 급여하면 장 내에 증가된 SCFA가 스카톨을 생산하는 미생물의 증식을 억제하여 분뇨 내 스카톨 농도를 저감하는데 효과적이라고 하였다 (Overland et al., 2011). $\mathrm{NH}_{4}{ }^{+}-\mathrm{N}$ 의 농도는 대조구, 땅콩껍질, 아몬드피 및 골든화이버 구에서 각각 $1,395,995$,

Table 3. Effects of Fermentable carbohydrate sources on the $\mathrm{VOC}, \mathrm{NH}_{4}{ }^{+} \mathrm{N}$ and $\mathrm{pH}$ from slurry of pigs ${ }^{1)}$

\begin{tabular}{|c|c|c|c|c|c|}
\hline \multirow{2}{*}{ VOC (ppm) } & \multicolumn{4}{|c|}{ Fermentable carbohydrate source } & \multirow{2}{*}{ SEM } \\
\hline & Control & Peanut hull ${ }^{2)}$ & Almond hull ${ }^{2)}$ & Golden fiber ${ }^{2)}$ & \\
\hline Phenol & $3.75^{\mathrm{a}}$ & $2.72^{b}$ & $2.88^{\mathrm{b}}$ & $2.09^{c}$ & 0.12 \\
\hline p-Cresol & $93.55^{\mathrm{a}}$ & $44.27^{\mathrm{b}}$ & $51.43^{\mathrm{b}}$ & $31.17^{\mathrm{c}}$ & 3.91 \\
\hline Indole & $0.97^{\mathrm{a}}$ & $0.87^{\mathrm{ab}}$ & $0.80^{\mathrm{ab}}$ & $0.65^{\mathrm{b}}$ & 0.05 \\
\hline Skatole & $0.82^{\mathrm{a}}$ & $0.39^{\mathrm{b}}$ & $0.40^{\mathrm{b}}$ & $0.37^{\mathrm{b}}$ & 0.04 \\
\hline Phenols $^{3)}$ & $97.29^{\mathrm{a}}$ & $46.99^{\mathrm{b}}$ & $54.31^{\mathrm{b}}$ & $33.26^{\mathrm{c}}$ & 3.99 \\
\hline Indoles $^{4)}$ & $1.79^{\mathrm{a}}$ & $1.27^{\mathrm{b}}$ & $1.20^{\mathrm{b}}$ & $1.02^{\mathrm{b}}$ & 0.07 \\
\hline $\mathrm{NH}_{4}^{+}-\mathrm{N}$ & $1,395^{\mathrm{a}}$ & $995^{\mathrm{ab}}$ & $995^{\mathrm{ab}}$ & $836^{\mathrm{b}}$ & 77.30 \\
\hline $\mathrm{pH}$ & 8.7 & 8.6 & 8.7 & 8.6 & 0.03 \\
\hline
\end{tabular}

${ }^{1)}$ Composition of pig diet : Protein $16.5 \%$, DE 3,450 kcal $/ \mathrm{kg}$, Fiber 3.4\%, Ca 0.8\%, P 0.65\%, Lysine 0.87\%, Methionine 0.27\%, Threonine $0.63 \%$, Tryptophan $0.19 \%$.

${ }^{2)}$ Composition of fermentable carbohydrate source : Peanut hull, Crude fiber $29.87 \%$, NDF 44.02\%; Golden fiber, Crude fiber $48.77 \%$, NDF $65.88 \%$; Almond hull, Crude fiber $44.30 \%$, NDF $64.44 \%$. Fermentable carbohydrate sources were added $0.5 \%$ in basic diet.

${ }^{3)}$ Phenols $=$ Phenol + p-Cresol

${ }^{4)}$ Indoles $=$ Indole + Skatole

${ }^{\mathrm{a}, \mathrm{b}, \mathrm{c}, \mathrm{d}}$ Figures with different superscripts within the same row are significantly different $(\mathrm{p}<0.05)$. 
995 및 $836 \mathrm{ppm}$ 으로 대조구에서 가장 높았으며, 골든화이 버 구에서 가장 낮았다 $(\mathrm{p}<0.05)$.

가축의 장내 또는 슬러리에서 발효과정 동안 미생물이 성장을 위해 필요로 하는 에너지가 제한요소로 작용되면, 미생물은 단백질을 에너지원으로 이용하기 때문에 많은 아 미노산이 분해되어 악취물질이 증가 될 수 있다. 따라서 다른 처리구에 비하여 골든화이버 구에서 $\mathrm{VOC}$ 의 농도가 가장 낮은 것은 골든화이버의 높은 $\mathrm{NDF}$ 함량으로 (Getachew et al., 2004) 단백질 발효보다 탄수화물 발효가 활발하게 일어났다고 추정된다.

\section{VI. 요 약}

양돈 사료에 발효탄수화물을 첨가하여 돼지의 슬러리에 서 악취물질의 농도를 평가하였다. VFA 분석결과, 분뇨의 SCFA 농도는 대조구, 땅콩껍질, 아몬드피 및 골든화이버 구에서 각각 $1,893,1,591,1,433$ 및 $1,319 \mathrm{ppm}$ 으로 대조구 에서 가장 높았고 $(\mathrm{p}<0.05)$, 아몬드피와 골든파이버 구에서 가장 낮았다 $(\mathrm{p}<0.05) . \mathrm{VFA}$ 의 구성을 살펴보면 $\mathrm{SCFA}$ 중에 서 아세트산의 비율이 가장 높으며, 다음으로 프로피온산, 부티르산, $\mathrm{BCFA}$ 순으로 낮았다. $\mathrm{BCFA}$ 의 농도는 대조구, 땅콩껍질, 아몬드피 및 골든화이버 구에서 각각 $98,92,78$ 및 $74 \mathrm{ppm}$ 으로 대조구에서 가장 높았고 $(\mathrm{p}<0.05)$, 골든화이 버 구에서 가장 낮았다 $(\mathrm{p}<0.05)$. $\mathrm{VOC}$ 분석결과, 분노의 페 놀류 농도는 대조구, 땅콩껍질, 아몬드피 및 골든화이버 구 에서 각각 97.3, 47.0, 54.3 및 $33.3 \mathrm{ppm}$ 으로 골든화이버 구 에서 가장 낮았으며, 대조구에서 가장 높았다 $(\mathrm{p}<0.05)$. 그 리고 $\mathrm{p}$-크레졸 농도가 페놀류 농도의 93 96\%를 차지하였 다. 인돌류 농도는 대조구, 땅콩껍질, 아몬드피 및 골든화 이버 구에서 각각 $1.8,1.3,1.2$ 및 $1.0 \mathrm{ppm}$ 으로 발효탄수화 물 처리구간에 차이가 없었으며 $(\mathrm{p}>0.05)$, 대조구에서 가장 높았다 $(\mathrm{p}<0.05) . \mathrm{NH}_{4}{ }^{+}-\mathrm{N}$ 의 농도는 대조구, 땅콩껍질, 아몬 드피 및 골든화이버 구에서 각각 $1,395,995,995$ 및 836 $\mathrm{ppm}$ 으로 대조구에서 가장 높았으며, 골든화이버 구에서 가 장 낮았다 $(\mathrm{p}<0.05)$. 가축의 장내 또는 슬러리에서 발효과정 동안 미생물이 성장을 위해 필요로 하는 에너지가 제한요 소로 작용되면, 미생물은 단백질을 에너지원으로 이용하기 때문에 많은 아미노산이 분해되어 악취물질이 증가 될 수 있다. 따라서 다른 처리구에 비하여 골든화이버 구에서 $\mathrm{VOC}$ 의 농도가 가장 낮은 것은 골든화이버의 높은 $\mathrm{NDF}$ 함량으로(Getachew et al., 2004) 단백질 발효보다 탄수화 물 발효가 활발하게 일어나 악취물질의 농도가 낮았다고 판단된다.

\section{$\mathrm{V}$. 사 사}

본 논문은 농촌진흥청 공동연구사업 (과제번호: PJ00923502) 의 지원에 의해 이루어진 것임

\section{REFERENCES}

Annual Research Report, Ministry of Environment, Korea. 2006.

Conn, K.L., Topp, E. and Lazarovits, G. 2007. Factors influencing the concentration of volatile fatty acids, ammonia and other nutrients in stored liquid pig manure. Journal of Environmental Quality. 36:440-447.

Cooper, P. and Cornforth, I.S. 1978. Volatile fatty acids in stored animal slurry. Journal of the Science of Food and Agriculture. 29:19-27.

Duncan, D.B. 1955. Multiple range and multiple F test. Biometrics. $11: 1-42$.

Getachew, G., Robinson, P.H., DePeters, E.J. and Taylor, S.J. 2004. Relationships between chemical composition, dry matter degradation and in vitro gas production of several ruminant feeds. Animal Feed Science and Technology. 111:57-71.

Gibson, G.R. and Roberfroid, M.B. 1995. Dietary modulation of the human colonic microbiota introducing the concept of prebiotics. Journal of Nutrition. 125:1401-1412.

Goa, Y., Rideout, T., Lackeyram, D., Archbold, T., Fan, M.Z., Squires, E.J., Duns C.F.M. de Lange, G. and Smith, T.K. 1999. Manipulation of hindgut fermentation to reduce the excretion of selected odor-causing compounds in pigs. In: Proceedings of Canadian Pork Council: Symposium of The Hog Environmental Management Strategy, Ontario, Canada, 24-29.

Jensen, B.B. and Jorgensen, H. 1994. Effect of dietary fiber on microbial activity and microbial gas production in various regions of the gastrointestinal tract of pigs. Applied and Environmental Microbiology. 60:1897-1904.

Jensen, M.T., Cox, R.P. and Jensen, B.B. 1995. 3-Methylindole (skatole) and indole production by mixed populations of pig fecal bacteria. Applied and Environmental Microbiology. 61:1803184

Kim, Y.I., Bae, J.S., Jung, S.H., Ahn, M.H. and Kwak, W.S. 2007. Yield and physicochemical characteristics of spent mushroom (Pleurotus ryngii, Pleurotus osteratus and Ammulina velutipes) substrates according to mushroom species and cultivation types. Korea Journal of Animal Science and Technology. 49:79-88.

Knarreborg, A., Beck, J., Jensen, M.T., Laue, A., Agergaard, N. and Jensen, B.B. 2002. Effects of non-starch polysaccharides on production and absorption of indolic compounds in entire male 
pigs. Animal Science. 74:445-453.

Korean Feeding Standard, swine, 2012. National Institute of Animal Science, RDA, Korea.

Le, P.D., Aarnink, A.J.A., Jongbloed, A.W., van der Peet-Schwering, C.M.C., Ogink, N.W.M. and Verstegen, M.W.A. 2008. Interactive effects of dietary crude protein and fermentable carbohydrate levels on odour from pig manure. Livestock Science. 114:48-61.

Le, P.D., Aarnink, A.J.A., Ogink, N.W.M., Becker, P.M. and Verstegen, M.W.A. 2005. Odour from animal production facilities: Its relationship to diet. Nutrition Research Review. 18: 3-30.

Lee, K.H., Hwang, O.H., Yang, S.H., Park, K.H., Lee, J.Y., Jeun, B.S., Ohh, S.J., Lee, S.S., Yoo, Y.H. and Cho, S.B. 2012. The effect of horseradish powder and mushroom waste in fattening pig diet on odorous compound concentration from slurry. Journal of Livestock House and Environment. 18:35-40.

Li, C.Y., Liu, J.X., Wang, Y.Z., Wu, Y.M., Wang, J.K. and Zhou, Y.Y. 2009. Influence of differing carbohydrate sources on Ltryptophan metabolism by porcine fecal microbiota studied in vitro. Livestock Science. 120:43-50.

Mackie, R.I. 1994. Microbial production of odor components. In International round table on swine odor control. pp. 18-19. Ames, IA, USA.

McGill, A.E.J. and Jackson, N. 1977. Changes in short chain carboxylic acid content and chemical oxygen demand of stored pig slurry. Journal of the Science of Food and Agriculture. 28:424-430.

Miller, D.N. and Varel, V.H. 2003. Swine manure composition affects the biochemical origins, composition, and accumulation of odorous compounds. Journal of Animal Science. 81:2131-2138.

Odor Control Law, Ministry of Environment, Korea. 2006.

Overland, M., Kjos, N.K., Fauske, A.K., Teige, L. and Sorum, H. 2011. Easily fermentable carbohydrates reduce skatole formation in the distal intestine of entire male pigs. Livestock Science. 140:206-217.

Parker, D.B., Lingshuang, C., Kim, K.H., Hales, K.E., Spiehs, M.J., Woodbury, D.L., Atkin, A.L., Nickerson, K.W. and Patefield, K.D. 2012. Reducing odorous VOC emissions from swine manure using soybean peroxidase and peroxides. Bioresource Technology. 124:95-104.

Reid, C.A. and Hillman, K. 1999. The effects of retrogradation and amylose/amylopectin ratio of starches on carbohydrate fermentation and microbial population in the porcine colon. Animal Science. 68:503-510.

Rideout, T.C., Fan, M.Z., Cant, J.P., Wagner-Riddle, C. and Stonehouse, P. 2004. Excretion of major odor-causing and acidifying compounds in response to dietary supplementation of chicory inulin in growing pig. Journal of Animal Science. 82:1678-1684.

SAS. 1996. SAS/STAT $\mathbb{R}$ software for PC. SAS Institute Inc., Cary, NC, USA.

Schaefer, J. 1977. Sampling characterization and analysis of malodours. Agricultural Environment. 3:121-127.

Spoelstra, S.F. 1977. Simple phenols and indoles in anaerobically stored piggery wastes. Journal of the Science of Food and Agriculture. 28:415-423.

Spoelstra, S.F. 1980. Origin of objectionable odorous components in piggery wastes and the possibility of applying indicator components for studying odour development. Agricultural Environment. 5:241-260.

Sutton, A.L., Kephart, K.B., Verstegen, M.W., Canh, T.T. and Hobbs, P.J. 1999. Potential for reduction of odorous compounds in swine manure through diet modification. Journal of Animal Science. 77:430-439.

Williams, A.G. and Evans, M.R. 1981. Storage of piggery slurry. Agricultural Wastes. 3:11-321.

Willing, S., Losel, D. and Claus, R. 2005. Effects of resistant potato starch on odor emission from feces in swine production units. Journal of Agricultural Food Chemistry. 53:1173-1178.

Wu, J.J., Park, S.H., Hengemuehle, S.M., Yokoyama, M,T., Person, H.L., Gerrish, J.B. and Masten, S.J. 1999. The use of ozone to reduce the concentration of malodorous metabolites in swine manure slurry. Journal of Agricultural Engineering Research. 72:317-327.

Zahn, J.A., Dispirotp, A.A., Do, Y.S., Brooks, B.E., Cooper, E.E. and Hatfield, J.L. 2001. Correlation of human olfactory responses to airborne concentration of malodorous volatile organic compounds emitted from swine effluent. Journal of Environmental Quality. 30:624-634

(Received November 5, 2013/Revised November 13, 2013/Accepted November 18, 2013) 